\title{
ANOREXIA NERVOSA AS AN ADVERSE EFFECT OF MEDICATION IN A CASE OF CHRONIC SCHIZOPHRENIA
}

Mary C. D'souza1', Deepak Ramnathkar²

\section{HOW TO CITE THIS ARTICLE:}

Mary C. D'souza, Deepak Ramnathkar. "Anorexia Nervosa as an Adverse Effect of Medication in a Case of Chronic Schizophrenia". Journal of Evolution of Medical and Dental Sciences 2015; Vol. 4, Issue 08, January 26; Page: 1374-1376, DOI: 10.14260/jemds/2015/191

ABSTRACT: INTRODUCTION: A 24 year old male patient presented to our department with anorexia nervosa in a long standing case of schizophrenia on treatment with resperidone and sodium valproate. The excessive weight gain due to side effect of medications resulted in development of anorexia nervosa in the patient. RESULT \& CONCLUSION: We present this interesting case for its rarity and also to demonstrate how the use of the side effect of another medication can prove beneficial for therapeutic purpose.

KEYWORDS: chronic schizophrenia, Anorexia Nervosa (A.N), Resperidone, Adverse effects, Olanzapine.

INTRODUCTION: Anorexia Nervosa is a relatively rare disorder predominantly seen in females.The ratio of men to women being approximately 1:10 to 1:20.(1) The term atypical Eating Disorder is often applied to conditions not meeting the full criteria for AN. ${ }^{(1,2)}$

The prevalence of AN co morbid with other psychiatric disorders has been reportedly high with Depression and Anxiety Disorders being commonest. $(2,3,4)$ AN and Schizophrenia presenting together is a rare phenomenon. There have been some single case reports or case series in favour of this dual diagnosis in female patients. ${ }^{(5,6)}$ The case we present is a chronic Schizophrenic male patient who after 5years of Schizophrenia on treatment developed AN secondary to antipsychotic and sodium valproate combination. He showed significant response after switching over to Olanzapine both in AN and Schizophrenia. $(7,8)$

MATERIALS \& METHOD: This report is written on the bases of the patient's structured clinical case file and the experience of the treating psychiatrist. The psychiatric diagnosis is based on ICD 10 Criteria. Clearance from the local Ethics committee and consent was obtained from the patient. The author reviewed Pubmed, PSYCH info, articles and reports for the purpose.

CASE REPORT: Mr. AB, 24years old male, first reported to Institute of psychiatry and Human Behaviour, Bambolim, Goa in 2009, with complaints of hearing voices, persecutory delusions against his father, brother and neighbours, neglect of self-care, hygiene and social withdrawal for more than 6 months. He was diagnosed with Paranoid Schizophrenia and started on Resperidone 2mgs and gradually increased to 6mgs over next few months. Since there was partial response and marked impulsivity towards relatives, Sodium Valproate was added as augmenter. Patient was reportedly better with Resperidone 6mgs and Sodium Valproate $1 \mathrm{gm}$ for next 2 years however was noticed to have gained weight from 65kgs to 85kgs. In 2012 patient presented to the Institute with severe weight loss, decreased food intake, feeling scared of becoming 'fat'. According to patient's mother, would be eating everything and inducing vomiting anywhere from 5 to 50 times in a day. Patient had constipation and would self-medicate with laxatives like Dulcolax, Ayurvedic preparations. 
On examination patient appeared as tall thinly built, young male, adequately dressed, normal psychomotor activity, with persecutory delusions against his brother. Patient denied any hallucinations. He expressed concern over weight gain and fears of becoming 'fat'. Rest mental status examination was within normal limit. His physical examination revealed mild pallor, pulse rate being 70 per minute, blood pressure of $110 / 70 \mathrm{mmHg}$ in lying down position. He had mild oedema feet. His height was $180 \mathrm{cms}$ and weight 55kgs with a BMI of 17 . His routine investigations showed a low Haemoglobin of 9gm\%.Complete hemogram revealed sideropenic anaemia. Rest investigations like LFTs, RFTs, TFTs were within normal limits. His ultrasound abdomen, CT scan/MRI brain were nil contributory.

Patient was started on Olanzapine (10mgs) and was gradually increased to $30 \mathrm{mgs}$ with nutritional counselling and psychotherapy. At 6 months follow up he showed a weight gain of 10 kgs(from 55kgs to 65kgs). He had completely stopped puking and purging during his follow up sessions.

DISCUSSION: The patient discussed here is a 25yrs old male with duration of paranoid schizophrenia being more than 5yrs and presenting with features resembling that of atypical Anorexia Nervosa.(1,9) Patient though he had classical paranoid delusions against his family and neighbours, did not express delusions regarding food, for example food being poisoned or feeling that he was being drugged through his food which is a regular phenomenon in paranoid schizophrenics.(5,9) This is clear from the fact that he was eating everything that was given to him. Patient expressed a morbid fear of becoming fat, but there were no delusional body image disturbances.(10,11) Patient did not have any loss of appetite, pervasive sadness of mood or other depressive features.

The patient was investigated to rule out any medical problem which may cause weight loss. There was no gastric obstruction, Crohn's disease or cerebral tumours found on investigation.(11,12)

The reason for weight gain in our patient would probably be the antipsychotic, resperidone and sodium valproate which is often implicated as the adverse effect of these medications. ${ }^{13,14)}$ There have been some rare case reports of patients of Anorexia Nervosa doing better with Olanzapine.(15) Keeping in mind our patient's primary diagnosis and the obvious need for weight gain, Olanzapine was considered as a favourable drug of treatment.(16)

CONCLUSION: Anorexia Nervosa is a rare eating disorder in Schizophrenia, especially in male population. Atypical antipsychotics and sodium valproate are commonly implicated in weight gain as side effect. A combination of dietary supplementation, psychotherapy, and the judicious use of Olanzapine resulted in a positive outcome in treatment of schizophrenia and Anorexia Nervosa.

\section{REFERENCES:}

1. Allan Jasman, Jerald Kay, Jeffery Liebermann; Psychiatry, 2nd Edition, vol. 2,ch 75,Eating Disorders: page 1503.

2. Halmi KA, Eckert E, Marché P, et al, Co morbidity of psychiatric diagnosis in Anorexia Nervosa. Archives of General Psychiatry 1991; 48: 712-718.

3. Bruch $\mathrm{H}$; ; the golden cage: the Enigma of Anorexia Nervosa. Cambridge Mass: Harvard University Press; 2001 (original published in 1978).

4. Halmi KA, Romano SJ, Anorexia Nervosa an overview, Primary Psychiatry 2001; 8: 35-56. 


\section{CASE REPORT}

5. Yum SY, Hwang MY, Yum SK; Predictors of disinhibited eating in restrained eaters in patients of Schizophrenia. Obesity Res. 2005; 13 (Sep Supp.); A71.

6. Ceaser Munoz, William G Ryan; Late onset Anorexia Nervosa in Schizophrenia: case report, Annals of Psychiatry, 1997, vol 9, no 2, pages 109-111.

7. Hwang MY, Yum SY, Hamayun A; Antipsychotic treatment of Obesity and metabolism in Schizophrenia. In Program and abstract of the Annual Meeting of American Psychiatric Association, May23, 2005; Atlanta Abstract NR 183.

8. Cinemre B, Kulaksizoghu B; case report:co morbid Anorexia Nervosa and Schizophrenia in a male patient. Turk Psikiyatri Derg, 2007 spring; 18 (1): 87-91.

9. Weckowicz TE, Sommer R,;Body image and self-concept in schizophrenia; Journal of mental Science 1960, 106: 17-19.

10. Bryzozowika A, Wolanczyk T, Komender J.: Patients with Anorexia Nervosa;Literature review and report of 3 cases; Psychiatric Pol. 1998 May-jun; 32 (3): 265-74.

11. Halmi KA,Lopez, Ibor JJ, Sartorius N, eds Eating Disorders; Classification, Diagnosis and co morbidities of eating disorders,a review, Chichester England Wiley 2003: 1-33.

12. Elizabeth Dadic Hero, Klementina Ruzic Tanja Grahrvac, Toni Petravaic; Treatment strategy in Schizophrenia combined with Eating Disorder; Psyciatrica Danubina 2011, vol 23 No 1 pg 9597.

13. Col. PK Pardel, Raaj Konwar; Olanzapine in the management of Anorexia Nervosa: A case report, IJP, Year 2011 vol 53, issu 5; Posters, Supp. S1,73-109.

14. Dunican KC, Delmotto D; the role of Olanzapine in the treatment of Anorexia Nervosa. Ann. Pharmacothe. 2007; 41: 111-115.

15. Jenson VS, Mejlhede A Anorexia Nervosa: treatment with Olanzapine, the British Journal of Psychiatry 2000: 177-87.

16. Dadic Hero E, Ruzic K, Kabalin M, Medved P; Olanzapine treatment in Anorexia Nervosa, Case report, Psychiatrica Danubi; 21: 122-125.

\section{AUTHORS:}

1. Mary C. D'souza

2. Deepak Ramnathkar

\section{PARTICULARS OF CONTRIBUTORS:}

1. Assistant Professor, Department of Psychiatry, Goa Medical College, Bambolim.

2. IMO, ESI Dispensary, Consultant in Psychiatry, Kundiam.

\section{NAME ADDRESS EMAIL ID OF THE CORRESPONDING AUTHOR:}

Dr. Mary D'souza, Assistant Professor, Institute of Psychiatry \& Human Behavior, Bambolim, Goa.

E-mail: mary.dsouza01@rediffmail.com

Date of Submission: 04/01/2015.

Date of Peer Review: 05/01/2015.

Date of Acceptance: 16/01/2015.

Date of Publishing: 24/01/2015. 